\title{
Evidential Arguments from Evil and the "Seeability" of Compensating Goods
}

\section{Justin McBrayer}

University of Missouri

William Rowe has offered one of the most simple and convincing evidential arguments from evil by arguing that the existence of gratuitous cvil in our world serves as strong evidence against the claim that God exists. Stephen J. Wykstra attempts to defeat this evidential argument from evil by denying the plausibility of Rowe's claim that there are gratuitous evils in the world. Wykstra sets up an epistemological test that he refers to as CORNEA, and he proceeds to demonstrate that Rowe's inference to his existential claim is unjustified in light of our particular epistemic situation. Specifically, this inference is unjustified because compensating goods that would be "connected to" any given evil lack what Wykstra calls 'seeability.' Without seeability, it is illicit to infer the nonexistence of an object simply from the fact that we cannot detect it, and thus Rowe is denied justification for his first premise. Wysktra's principle defense of the non-seeability of compensating goods rests on an analogy comparing children and parents to humans and God.' I will show that Wykstra's conclusion regarding the seeability of compensating goods is unjustified given this analogy. Without justification for the claim that some compensating goods lack seeability, Wykstra's defeater crumbles.

First I need to reconstruct Wykstra's criticism in order to demonstrate the crucial role of seeability in his defeater, and then I will criticize his application of the parent analogy. Rowe's original evidential argument from evil begins with the existential claim that gratuitous evil exists, then notes that if God exists then there will not be any gratuitous evil, and concludes via modus tollens that God does not exist. ${ }^{2}$ Wykstra converts Rowe's existential claim concerning gratuitous evils into the logically-equivalent claim regarding the existence of compensating goods for some evils. ${ }^{3}$ In other words, Wykstra demands that Rowe defend the claim that there are no compensating goods for some evils. Rowe's 
"Nosceum" argument does so, according to Wykstra, by A) noting that we do not see any compensating goods, B) then claiming that there appear to be no compensating goods, and finally $\mathrm{C}$ ) concluding that there are no compensating goods. ${ }^{4}$ Wykstra endorses Chisolm's principle of credulity which states that "if something appears to be a certain way, then, provided there is no counterevidence, it is reasonable for us to believe that $\mathrm{X}$ is that way," and so he accepts Rowe's move from (B) to (C). What he rejects is Rowe's inference from (A) "we see no compensating goods" to (B) "there appears to be no compensating goods."

This is a strange form of argumentation, as Wykstra seems to indicate that appearance states can fail to be justified while justification is a notion that is usually reserved for beliefs. ${ }^{6}$ Both (A) and (B) are basically appearance states while only (C) is a belief state. I'm not sure that Rowe would accept Wykstra's odd reformulation of his argument, but I think that this oddity, while confusing, is not ultimately fatal to Wykstra's critique. All he must generate is a defeater that will block the conclusion normally allowed by the principle of credulity, and he thinks that CORNEA provides just that. Going forward I will continue to use Wkystra's terminology and formulation, while noting that his argument is readily converted into an argument for a defeater that will provide counterevidence blocking the move from the appearance state (B) to the belief state $(\mathrm{C})$ via the principle of credulity. ${ }^{7}$

In order to justify his move from (A) to (B), Wykstra demands that Rowe submit his inference to a test regarding the conditions of reasonable epistemic access (CORNEA). CORNEA is Wykstra's heuristic tool for evaluating 'appears' claims:

CORNEA says that a situation of seeing no $X$ justifies one's claiming "it appears there is no X" only if it is reasonable for one to believe that $\mathrm{X}$ is something to which we would likely have "epistemic access" in the situation....CORNEA says that Rowe's noseeum situation justifies his appears claim only if $i t$ is reasonable for Rowe to believe that a God-justifying good for the fawn's suffering would likely be "seeable."

"Seeability" is thus the crucial issue. If Rowe can demonstrate 
the subjunctive claim that compensating goods would be seeable given our epistemic condition, then he is licensed to cstablish his "appears" claim. If, however, we are justified in concluding that compensating goods would not be seeable given our epistemic condition (or if we are unable to make any justified conclusion regarding the secability of goods), then Rowe is prohibited from his "appears" claim, and his evidential argument fails.

The determination of whether or not something has seeability is thus the crucial element in Wykstra's critique. He employs what he calls the Adjunct Principle to clarify the epistemic conclusion of seeability:

If Rowe is made aware of good reasons for thinking that Godjustifying goods would lack seeability, then conditionally (i.e. unless Rowe defeats these with other considerations), it is not reasonable for Rowe to believe that these goods would be seeable. ${ }^{9}$

The central issue at hand, then, is whether or not, given our epistemic condition, we have good reasons to think that compensating goods would be seeable.

Wykstra concludes that we are justified in believing that compensating goods (if they existed) would lack seeability, and he supports this conclusion with what he calls the parent analogy:

Given what we independently know of our cognitive limits, I [suggest] that the vision of such a being might well be to ours, as a parent's is to that of a one-month-old human infant.... [and regarding compensating goods] that we should discern most of them seems about as likely as that a one-month-old should discern most of his parent's purposes for those pains they allow him to suffer-which is to say, it is not likely at all..$^{10}$

Prima facie, Wykstra's analogy is useful. If God exists in traditional form, then his understanding and knowledge would far surpass that of any finite creation. And just as surely, a parent has an understanding and knowledge that far surpasses that of an infant. Wykstra ends the analogy here with the conclusion that just as it is 
unsurprising that a parent have knowledge of compensating goods that the child cannot fathom, so too it is unsurprising that God would have knowledge of compensating goods which we cannot fathom.

The general structure of the parent:child :: God:man analogy is instructive. But I think, pace Wykstra, that the analogy can be extended to defend Rowe's inference from (A) to (B). It seems to me that Rowe can establish a reasonable justification for the seeability of compensating goods by reformulating Wykstra's parent analogy. Contra Wykstra, this comparison provides at least some justification for the claim that compensating goods would be seeable.

Here is one suggestion as to how Rowe might use the parent analogy to defend his claim that there appear to be no compensating goods for evils in our world. The analogy would be more appropriate if we considered the relationship between a kind and loving parent and his child. God is omni-benevolent, so this alteration is, if anything, an improvement. A loving parent will always want the best for his child, and at times, this means that the child must endure some pain, hardship or suffering in order to achieve some compensating good. Because such suffering is difficult and intrinsically evil, a loving parent will do all he can to ensure that the child is able to "see" the compensating good that requires the suffering in question. A parent who is able to ensure that his child can "see" the compensating good but who instead obscures the good from the child's recognition is not loving at all but crucl. Loving parents, then, ensure that their children can see the compensating goods whenever this is possible.

Wykstra might object that children (especially infants), regardless of how much the parent would like the child to see them, cannot "see" compensating goods. For example, a young child who must undergo months of chemotherapy cannot just "see" the compensating benefit to his terrible suffering. I think that this objection is on the right track. But suppose we take another look at the parent analogy. Notice that when a loving parent is unable to ensure that the child can "see" the compensating good, he makes every effort to explain the compensating good to the child, and he continually assures his child that this compensating good exists. 
When a young child requires a painful inoculation, the loving parent sits him down and explains the reasoning behind the injection. Even though the child cannot "see" the benefit of being vaccinated, his parent takes great measures to assure him that the pain is necessary for some greater end. I think it reasonable to conclude that when a loving parent cannot ensure that his child can "see" the compensating good, he provides sound assurances that this sort of good exists and that the present suffering is not gratuitous. Wykstra might agree with the foregoing analysis and yet raise a new objection. Recall that the original analogs are a human parent and an infant. Parents cannot communicate to an infant the sort of information that we have been considering. This is because no matter how much the parent may want to communicate with the infant, the infant's mental abilities effectively prohibit communication. Perhaps, due to the vast difference between our mental abilities, God is simply unable to comfort and assure us in the ways that I have suggested. Or, alternatively, perhaps God has communicated this assurance, but we just haven't understood it. I take it that this latter objection isn't very convincing, as I can imagine no way of defending it that will not preclude our having understood God's communication in the first place.

But consider the former option-perhaps our mental abilities are so deficient that God cannot communicate this sort of information to us. Again Wykstra's parent analogy requires some adjustments. It is certainly true that human parents can't fully communicate with infants (though they can interact with infantse.g. comforting them, nurturing them, etc.). But as a theist, I assume that Wykstra believes that God communicates with his creationespecially humans. The Christian God, at least, has communicated all sorts of things to us, including moral principles, promises, prophecies, etc. In short, it won't do for Wykstra to deny that communication concerning the existence of compensating goods is possible. It appears that the parent analogy must be refined again to reflect the relationship between a loving parent and a child who is old enough to understand basic communication. But if we revise the analogy in this way, the most recent objection (that communication on the topic of suffering and compensating goods is impossible) fails. 
In short, the parent analogy, which serves as Wykstra's sole justification for his conclusion that compensating goods would lack "seeability," turns out to provide Rowe with precisely the justification that his argument needs. If he can extend the parent analogy in the directions that I have suggested, then Rowe can meet the standards of the Adjunct Principle by demonstrating that, given theism, it is likely that we would know about the existence of compensating goods, and his inference will then meet the test of CORNEA by showing that compensating goods have a high level of seeability. With the CORNEA test satisfied, Rowe is licensed to conclude that seeing no compensating goods (A) can justify the claim that there are no compensating goods (C). With rational support for the claim that no compensating goods exist, Rowe has justification for the belief that gratuitous evils exist, and his evidential argument against the existence of God is a success.

\section{Notes}

' Stephen John Wykstra. 1996. "Rowe's Noseeum Arguments from Evil," The Evidential Argument from Evil, Daniel Howard-Snyder (ed.). Bloomington: Indiana University Press. 139-140.

${ }^{2}$ This is an accurate, if shortened, restatement of Rowe's argument. To see the argument in its full form, refer to William Rowe, "The Problem of Evil and Some Varieties of Atheism," American Philosophical Quarterly, 16: 336, 1979.

${ }^{3}$ The exact wording of Rowe's first premise is as follows: "There exist instances of intense suffering which an omnipotent, omniscient being could have prevented without thereby losing some greater good or permitting some evil equally bad or worse." William Rowe, "The Problem of Evil and Some Varieties of Atheism," American Philosophical Quarterly, 16: 336, 1979.

4 Stephen John Wykstra. 1996. "Rowe's Noseeum Arguments from Evil," The Evidential Argument from Evil, Daniel Howard-Snyder (ed). Bloomington: Indiana University Press. 127.

${ }^{5}$ Ibid, 127.

${ }^{6}$ This observation is due to Jon Kvanvig.

${ }^{7}$ I need to thank Jonathan Kvanvig for helpful comments regarding this confusion in an earlier draft of this paper.

${ }^{8} \mathrm{Ibid}, 128 ; 129$, emphasis Wykstra's.

${ }^{9} \mathrm{Ibid}, 136$.

${ }^{10}$ Ibid, 139. 